\title{
DETERMINANTES DAS POLÍTICAS EDUCACIONAIS NO BRASIL CONTEMPORANEO: RISCO À DEMOCRACIA?
}

\author{
DETERMINANTS OF EDUCATIONAL POLICIES IN CONTEMPORARY \\ BRAZIL: RISK TO DEMOCRACY? \\ DETERMINANTES DE LAS POLÍTICAS EDUCACIONALES EN BRASIL \\ CONTEMPORÁNEO: ¿RIESGO A LA DEMOCRACIA?
}

Rosalba Maria Cardoso Garcia*

(iD) http://orcid.org/oooo-ooo3-3260-6982

\begin{abstract}
REVISTA PEDAGÓGICA
Revista do Programa de Pós-graduação em Educação da Unochapecó | ISSN 1984-1566 Universidade Comunitária da Região de Chapecó | Chapecó-SC, Brasil Como referenciar este artigo: GARCIA, R. M. C. Determinantes das políticas educacionais no Brasil contemporâneo: risco à democracia? Revista Pedagógica, Chapecó, v. 22, p. 1-17, 2020.

DOI: https://doi.org/10.22196/rp.v22io.4374
\end{abstract}

Resumo: A discussão proposta aborda determinantes políticos e econômicos das políticas educacionais no Brasil. Na primeira seção buscou-se discutir uma base conceitual para compreender o golpe de Estado de 2016. A segunda seção contempla a discussão da tese do risco à democracia face à conjuntura política nacional. A terceira seção apresenta elementos para apreender o caráter das políticas educacionais na conjuntura atual brasileira. Foram mobilizados os conceitos de golpe de Estado, democracia e mercantilização. Procurou-se discutir que não houve nas políticas educacionais ampliação ou estreitamento da democracia burguesa, mas alterações na forma política pela qual ela passa a ser praticada aprofundando os riscos às lutas da classe trabalhadora.

Palavras-chave: Política educacional. Democracia. Mercantilização.

Abstract: The proposed discussion addresses the political and economic determinants of educational policies in Brazil. In the first section we sought to discuss a conceptual basis for understanding the coup d'état of 2016. The second section contemplates the discussion of the thesis of the risk to democracy in face of the conjunctural national policy. The third section presents elements to apprehend the character of educational policies in the current Brazilian conjuncture. The concepts of coup d'état, democracy and mercantilization were mobilized. We tried to argue that there was no expansion or narrowing of bourgeois democracy in educational policies, but changes in the political form by which it is practiced by deepening the risks to the struggles of the working class.

Keywords: Educational politics. Democracy. Commodification.

Resumen: La discusión propuesta aborda determinantes políticos y económicos de las políticas educativas en Brasil. En la primera sección se buscó discutir una base conceptual para comprender el golpe de Estado de 2016. La segunda sección contempla la discusión de la tesis del riesgo a la democracia frente a la coyuntural política nacional. Se movilizaron los conceptos de golpe de Estado, democracia y mercantilización. Buscamos discutir que no hubo en las políticas educativas ampliación o estrechamiento de la democracia burguesa, sino cambios en la forma política por la cual ella pasa a ser practicada profundizando los riesgos a las luchas de la clase trabajadora.

Palabras clave: Política educativa. Democracia. Mercantilización. 


\section{Introdução}

A discussão aqui proposta aborda determinantes políticos e econômicos das políticas educacionais no Brasil na forma de um ensaio estruturado em três seções. $\mathrm{Na}$ primeira seção buscou-se discutir a conjuntura de golpe de Estado impetrado no país no período do governo Dilma Rousseff articulada a uma base conceitual que favoreça sua compreensão. A segunda seção contempla a discussão da tese do risco à democracia face à conjuntura política nacional. A terceira seção foi elaborada com vistas a apresentar elementos que permitam apreender o caráter das políticas educacionais na conjuntura atual brasileira. No caminho percorrido foram mobilizados os conceitos de golpe de Estado, democracia e mercantilização.

\section{Uma conjuntura de golpe de estado no Brasil contemporâneo}

A conjuntura política brasileira a partir de 2016 tem intensificado a necessidade constante de desenvolver reflexões acerca de temas complexos como a democracia e as políticas sociais nos limites postos pelo capital. O fortalecimento do pensamento conservador e suas diferentes expressões políticas é base do alargamento e aprofundamento de fenômenos sociais observáveis e que justificam a preocupação de compreensão da realidade social em movimento. O golpe de natureza jurídica, midiática e parlamentar empreitado pela burguesia no Brasil constitui uma síntese dos fenômenos sociais mencionados ao mesmo tempo em que, se articulado conceitualmente, pode possibilitar, ao menos em parte, a compreensão de um encadeamento de situações que envolvem a organização do Estado brasileiro, a relação com as políticas sociais e dentre elas um debate acerca da política educacional em curso no Brasil. ${ }^{1}$

Bianchi (2016) desenvolveu uma síntese do conceito de golpe de Estado mediante a recuperação de estudos anteriores e buscando uma atualização do conceito às condições históricas. Segundo o autor

O conceito deve deixar claro quem é o protagonista daquilo que se chama coup d'état, os meios que caracterizam a ação e os fins desejados. O sujeito do golpe de estado moderno é, como Luttwak destacou, uma fração da burocracia estatal. $\mathrm{O}$ golpe de estado não é um golpe no Estado ou contra o Estado. Seu protagonista se encontra no interior do próprio Estado, podendo ser, inclusive, o próprio governante. Os meios são excepcionais, ou seja, não são característicos do funcionamento regular das instituições políticas. Tais meios
* Doutora em Educação pela Universidade Federal de Santa Catarina. Professora do Programa de Pós-Graduação em Educação da UFSC.

E-mail: rosacampeche@uol.com.br

1 Acerca da capacidade de reflexão sobre o golpe de 2016 no Brasil foram anunciadas publicamente a realização de cursos em ao menos 30 universidades brasileiras. Diário on line Causa Operária. 26 de março de 2018. 
se caracterizam pela excepcionalidade dos procedimentos e dos recursos mobilizados. O fim é a mudança institucional, uma alteração radical na distribuição de poder entre as instituições políticas, podendo ou não haver a troca dos governantes. Sinteticamente, golpe de estado é uma mudança institucional promovida sob a direção de uma fração do aparelho de Estado que utiliza para tal de medidas e recursos excepcionais que não fazem parte das regras usuais do jogo político (BIANCHI, 2016, p. 6).

Ao aplicar o conceito aos fatos de 2016 no Brasil apreendemos uma ação coordenada dos poderes legislativos, judiciário e executivo amalgamados pela ação discursiva e imagética da mídia corporativa. Podemos inferir que mais do que uma fração da burocracia estatal, o protagonismo do golpe de 2016 foi assumido por uma fração da burguesia interna brasileira instalada nos poderes da república e articulada ao grande capital financeiro internacional (BOITO JR., 2007). Segundo o autor, teria havido sob a mediação política do governo Lula da Silva (2003-2010) uma convivência entre o grande capital financeiro internacional e a ascensão política da grande burguesia interna brasileira no interior do bloco no poder. O golpe de 2016 se constrói, entre outros motivos, em torno da dissolução desse sensível equilíbrio e o conjunto de políticas sociais compensatórias e voltadas ao mercado interno, desenvolvidas pelos governos do PT. ${ }^{2}$ Embora insuficientes do ponto de vista da classe trabalhadora e das suas necessidades históricas de desenvolvimento social, humano, político, tais mediações políticas internas conflitaram com os interesses do grande capital internacional. A articulação ideológica de índices econômicos desfavoráveis à administração pública do governo Dilma Rousseff, a atuação coordenada do judiciário, do legislativo e a capitalização política das manifestações de rua conduziram Michel Temer à presidência da república como ponta de lança do novo bloco no poder. A finalidade do golpe de estado foi atingida conforme a reflexão de Bianchi (2016, p. 6) com "a alteração radical na distribuição de poder entre as instituições políticas, podendo ou não haver a troca dos governantes". O golpe colocou como novo programa político nacional a proposta "Ponte para o futuro", do então Partido do Movimento Democrático Brasileiro - PMDB, o qual não foi apreciado publicamente seguindo as práticas da democracia participativa ou aprovado pelas regras da democracia representativa pela via do voto direto. ${ }^{3}$
2 Mandatos Lula da Silva (2003-2006 e 2007-2010) e mandatos Dilma Rousseff (2011-2014 e 2015-2016).

3 Ao final do ano de 2017 o nome e a sigla do Partido do Movimento Democrático Brasileiro - PMDB foi alterado para MDB. 


\section{O golpe de 2016: reflexões acerca do risco à democracia}

Após o processo de impedimento da presidenta Dilma Rousseff ${ }^{4}$ e da entrada em curso das políticas encaminhadas pelo governo Michel Temer, fez-se notar um conjunto de manifestações públicas de associações, grupos independentes, sindicatos, vinculadas à área da educação no Brasil em relação ao risco que o golpe ofereceu à democracia, à desconstrução de direitos sociais com uma série de propostas que inviabilizam o financiamento das políticas públicas e à defesa do direito à educação como elemento constituinte de uma sociedade democrática. ${ }^{5}$

Propomos nessa seção refletir sobre alguns elementos que contribuam para relacionar democracia e políticas sociais como objetos de disputa em meio ao fortalecimento do pensamento conservador como base para pensar a educação básica no Brasil no momento presente.

Uma primeira reflexão para tematizar a questão da democracia é: qual democracia? Ao pensarmos que a democracia está em risco, de qual democracia estamos tratando? No século XXI no Brasil, e desde as revoluções burguesas na Europa no século XVIII (HOBSBAWM, 1996), o objeto de estudo democracia localiza-se historicamente em relações de produção capitalista, portanto, como parte de relações políticas que acompanham a formação social capitalista. $\mathrm{O}$ adjetivo capitalista ou burguês é necessário para o entendimento e precisão conceitual do objeto de estudo - trata-se de uma democracia burguesa, portanto, de uma democracia erigida sobre relações de expropriação e exploração econômica e dominação cultural de uma classe social sobre a outra (MARX, 1985). Na complexidade dessa relação entre classes, capital e trabalho, no campo do trabalho emergem uma infinidade de identidades e subjetividades, agrupamentos e organizações de lutas, algumas na ordem, outras contra a ordem.

A democracia como conceito pode ser pensada, contraditoriamente, como funcional ao sistema capitalista ou como base para a luta política contra o capital. Além disso, é preciso articular também as contradições em sua face estrutural e conjuntural.

Na primeira acepção, como funcional ao sistema capitalista temos, conforme a historiadora Ellen Wood, que o capitalismo tornou possível uma democracia limitada, "formal" antes que "substantiva" (MÈSZÀROS, 2017). E é por isso que o capital pode tolerar algum tipo de democracia (WOOD, 2007, p. 417). A democracia burguesa, portanto, limitada, formal e funcional ao capitalismo, não está ela própria necessariamente em risco. Ela pode ser assegurada nos limites de um formato representativo burguês no qual

4 Processo consumado em 31 de agosto de 2016.

5 No caso da educação, especial destaque para a $38^{\mathrm{a}}$ Reunião Nacional da Associação Nacional de Pesquisa e Pós-Graduação em Educação - ANPED, cuja temática foi "Democracia em risco: a pesquisa e a pós-graduação em contexto de resistência", realizada em outubro/2018 em São Luís/MA. 
formalmente escolhemos entre propostas que não representam uma distinção de projetos para organizar a sociedade, mas escolhemos entre programas com variações sobre a forma política de encaminhar o mesmo projeto de sociedade. A democracia formal, ao acompanhar a materialidade de expropriação e exploração da classe trabalhadora e constituir uma formação social desigual, que somente tolera uma igualdade formal, contribui, igualmente, para colocar a classe trabalhadora em risco, em todas as suas faces e formas de organização. Nessa acepção a democracia burguesa não está rigorosamente em risco uma vez que convive com certa segurança com o pensamento conservador, com a corrupção e com outros elementos políticos que a tornam "necessária" ou "desejada". Em alguns casos, passa a ser requerida até mesmo pela classe trabalhadora em condição da mais profunda desigualdade. É o "canto da sereia" fazendo parecer que a sociedade capitalista pode, de fato, ser harmônica, igualitária, justa, para além do plano formal.

$\mathrm{Na}$ outra face da moeda a democracia estaria "contra o capitalismo”.

O capitalismo é - em sua análise final - incompatível com a democracia, se por "democracia” entendemos tal como o indica sua significação literal, o poder popular ou o governo do povo. Não existe um capitalismo governado pelo poder popular no qual o desejo das pessoas seja privilegiado aos dos imperativos do ganho e da acumulação e, no qual, os requisitos da maximização do beneficio não ditem as condições mais básicas de vida. O capitalismo é estruturalmente antitético em relação à democracia, em princípio, pela razão histórica mais óbvia: não existiu nunca uma sociedade capitalista na qual não tenha sido atribuído à riqueza um acesso privilegiado ao poder. Capitalismo e democracia são incompatíveis também, e principalmente, porque a existência do capitalismo depende da sujeição aos ditames da acumulação capitalista e às "leis" do mercado das condições de vida mais básicas e dos requisitos de reprodução social mais elementares, e esta é uma condição irredutível. Isso significa que o capitalismo necessariamente situa cada vez mais esferas da vida cotidiana fora do parâmetro no qual a democracia deve prestar conta de seus atos e assumir responsabilidades. Toda prática humana que possa ser convertida em mercadoria deixa de ser acessível ao poder democrático. Isso quer dizer que a democratização deve ir da mão da "desmercantilização”. Mas desmercantilização por definição significa o final do capitalismo (WOOD, 2007, p. 418). 
Nessa segunda acepção, o capitalismo, do ponto de vista estrutural, e não somente na atual conjuntura brasileira, representa risco à democracia. Mas a qual democracia? A democracia pensada como "poder popular", em relação à qual cabe melhor tratar da possibilidade de democratização da sociedade. Portanto, podemos pensar que a afirmação da estrutura capitalista em uma conjuntura permeada pelo ascenso do pensamento conservador significa risco à democratização da sociedade.

A forma política ganha importância tal como apresentado por Rancière (2014, p. 15) quando relata acerca do relatório intitulado "A crise da democracia", produzido por ocasião da "Conferência Trilateral". ${ }^{6}$ Em análise sobre os "riscos" produzidos pela democracia e apresentados pelos autores do referido relatório registra que

a democracia, [...], significa o aumento irresistível de demandas que pressionam os governos, acarreta o declínio da autoridade e torna os indivíduos e os grupos rebeldes à disciplina e aos sacrifícios exigidos pelo interesse comum. [...] A democracia parece ter dois adversários. De um lado, opõe-se a um inimigo claramente identificado, o governo do arbitrário, o governo sem limites que denominamos, conforme a época, tirania, ditadura ou totalitarismo. Mas essa oposição evidente esconde outra, mais íntima. $\mathrm{O}$ bom governo democrático é aquele capaz de controlar um mal que se chama simplesmente vida democrática (RANCIÈRE, 2014, p. 16).

O equilíbrio necessário para a ampliação/redução das práticas sociais democráticas, nos limites impostos pelo capital está indicado na análise. A democracia sob o capital necessariamente deve ser medida, cronometrada, de modo a não exceder "à disciplina e aos sacrifícios exigidos pelo interesse comum”.

Passamos então a discutir o que significa para a democratização da sociedade e para a educação no Brasil a democracia burguesa constitutiva da formação social do capitalismo imperialista na sua forma predominantemente financeira. Importante ressaltar a compreensão segundo a qual a educação não é apenas um setor de implementação de políticas e projetos, mas configura-se em arena de lutas, espaço privilegiado de disputas de projetos de sociedade, de educação e desenvolvimento humano.

\section{Reflexões sobre o caráter das políticas educacionais na conjuntura atual brasileira}

Tomaremos como um critério para analisar as políticas educacionais mais recentes no Brasil, visando refletir
6 Segundo RANCIÈRE (2014) a Conferência Trilateral foi uma comissão criada por representantes do Estado e do mercado de países da Europa Ocidental, Estados Unidos da América e Japão em 1973. Constam como autores do relatório "A crise da democracia": Michel Crozier, Samuel Hantington e Joji Watanuki. 
sobre a educação básica, a sinalização de que a democratização deve andar em contrário à mercantilização (WOOD, 2007).

O pensamento liberal, que tem reposto sua hegemonia em escala mundial, sugere que em nossas análises separemos o elemento político do econômico. Tal orientação para a análise repercute em considerar apenas a face conjuntural do golpe jurídico, midiático e parlamentar de 2016 como uma situação de risco para a democracia no Brasil. Ainda que o programa "Ponte para o Futuro"7 não tenha sido apresentado à sociedade e submetido ao voto popular, o que depõe com toda certeza contra um processo de democratização, os processos econômicos que o antecedem já davam conta de ínfimos investimentos nas políticas sociais e muita lucratividade aos bancos e ao capital financeiro de modo geral. Desde a década de 1970 a realidade com a qual nos defrontamos foi resumida por Granemman, da seguinte forma:

[...] as alterações na base produtiva, na estrutura do Estado e na cultura tornam o welfare state e as políticas sociais mecanismos não somente impróprios mas que também interpõem severos obstáculos para a realização das exigências do capital monopolista marcado pelas finanças, nos dias presentes. Para a dinâmica da acumulação do grande capital comandada pelas finanças, os equipamentos públicos formatados com base no acesso universal e que, recíproca e contraditoriamente, respondiam ao preceito fordista do consumo em massa, da circulação da moeda e da luta da força de trabalho por melhores condições de vida e trabalho, tornaram-se obsoletos. Se as políticas sociais do welfare state não mais se constituem para o capital como mediações para a elevação da extração de mais valia e se as lutas de classe não apresentam potencialidade suficiente para questionar a propriedade privada e promover a superação do presente modo de produção, elas devem ser superadas pela redução dos direitos do trabalho - direitos, em grande medida, viabilizados por políticas sociais - e por sua metamorfose em serviços privados (GRANEMANN, 2007, p. 58).

Ainda que no Brasil não tenhamos desenvolvido políticas de bem-estar social, o que preside o capital mundial na atualidade

[...] é estender a lógica das finanças para a totalidade da vida social e conformar uma sociabilidade na qual as políticas sociais
7 Disponível em https://www.fundacaoulysses.org.br/wp-content/uploads/2016/11/UMA-PONTE-PARA-O-FUTURO.pdf 
mínimas operadas pelo Estado sejam elementos de financeirização no cotidiano dos trabalhadores; aquilo que restar da contrareforma do Estado, dos sistemas de proteção social e dos direitos do trabalho passará a ser validado na esfera da monetarização da vida. [...] o capitalismo monopolista vincado pelas finanças determina um novo formato para as políticas sociais como uma necessidade essencial de reprodução da acumulação capitalista (GRANEMANN, 2007, p. 59).

O que significa dizer que antes de 2016 já estávamos vivendo um processo de inserção do país nas relações capitalistas na forma predominantemente financeirizada tal como descrito por Chesnais (2000), pelo menos desde os anos 1990. Segundo Chesnais (2000)

Os fundamentos da mundialização atual são tanto políticos como econômicos. É apenas na vulgata neoliberal que o Estado é 'exterior' ao 'mercado'. [...] O triunfo atual do mercado não poderia ser feito sem as intervenções políticas repetidas das instâncias políticas dos Estados capitalistas mais poderosos.

Em relação à previdência, por exemplo, a contra-reforma de Michel Temer foi antecedida por medidas que trouxeram alterações na aposentadoria nos governos de Fernando Henrique Cardoso (1995-2002), Lula da Silva e Dilma Rousseff. Em 2019 foi promulgada a Emenda Constitucional 103/2019 relativa à reforma da previdência encampada por Jair Bolsonaro (2019 -), com alterações mais profundas em relação aos direitos dos trabalhadores.

As políticas sociais e educacionais que foram implementadas desde 2016, guardadas as suas diferenças e detalhamentos procedimentais, foram formuladas e postas em prática nessa conjuntura econômica, foram desenvolvidas nessa lógica e não contra ela. Portanto, seguindo o critério de mercantilização como contrário à democratização, nesse quesito tivemos a preponderância da mercantilização. Entretanto, a análise exige cuidado em nossa posição intelectual e política ao nomear os processos sociais como democratização, para não produzir um esvaziamento do seu sentido.

Ainda que as políticas sociais dos governos do PT e sua base aliada, governando em regime de conciliação de classes, não tenham superado a "administração funcional da ordem burguesa” (ALVES, 2016), representaram o uso do fundo público para os setores sociais, dentre os quais a educação. Alves (2016) destaca o "grande assalto ao fundo público no Brasil” que representou o golpe de 2016, 
aprofundando a realidade de mercantilização das políticas sociais. Da mesma forma, a proposta de emenda constitucional (PEC 241) que estabeleceu um teto de gastos para a área social significou uma verticalização da ofensiva aos setores populares. Ainda que as políticas sociais já estivessem limitadas pela ação do Estado capitalista sob a batuta dos governos do PT, a nova investida representou uma disputa mais vigorosa pelo fundo público e sua transferência para a gestão privada foi um ingrediente fundamental das mudanças políticas no país. Para Fontes (2010) tais subtrações de direitos sociais dos trabalhadores podem ser apreendidas como expropriações secundárias.

Segundo FONTES (2007, p. 6)

O exacerbado processo atual de "mercantilização" é, de fato, um dos mais violentos momentos de expropriação social. As águas, o ar, a natureza biológica, sementes, gens humanos, etc. eram elementos naturais ou sociais sobre os quais não incidia propriedade e que vêm sendo arrancados da totalidade dos seres humanos e convertidos em propriedade. O que vem ocorrendo não é apenas "converter" em mercadoria algo que não o era, mas um efetivo processo social de expropriação. Não se trata apenas de converter coisas em mercadorias, mas de assegurar a permanência e expansão das relações sociais que nutrem o capitalismo.

As políticas sociais do governo Jair Bolsonaro pouco são notadas, em face de uma "expansão das relações sociais que nutrem o capitalismo" mediante a "participação direta empresarial em todos os ministérios e áreas estratégicas do Estado" (FONTES, 2019, p. 4).

Especificamente em relação à educação, as políticas do período anterior ao governo Temer já anunciavam e instalavam processos crescentes de privatização ou mercantilização. O movimento Todos pela Educação ${ }^{8}$ foi ícone nessas políticas em sua articulação com o Governo Lula da Silva na definição de um plano de metas para a educação, com interferência posterior sobre o Plano Nacional de Educação ${ }^{9}$ e sobre a Base Nacional Comum Curricular, ${ }^{10}$ dispositivos políticos fundamentais e com atuação hegemônica do setor privado. Diversos estudos têm sido dedicados a conhecer os processos de privatização da e na educação básica no Brasil demonstrando a compra e venda de "sistemas educacionais" entre empresas educacionais e prefeituras municipais, verdadeiros "pacotes" de serviços que envolvem apostilas, "treinamento" de professores e gestores escolares (KRAWCZYK, 2005; ADRIÃO e PERONI, 2009; ADRIÃO et al, 2009; ADRIÃO, 2014; ADRIÃO et al, 2016).
8 Fundado em 2006 por empresários como organização não governamental ONG, reorganizado em 2014 como Organização da Sociedade Civil de Interesse Público (OSCIP), entidade privada que atua em áreas específicas do setor público, podendo ser financiada pelo Estado ou iniciativa privada sem fins lucrativos. Tem como objetivos anunciados na mídia: propiciar as condições de acesso, de alfabetização e de sucesso escolar, a ampliação de recursos investidos na educação básica e a melhoria da gestão de recursos. Para o alcance desses objetivos o Movimento estabeleceu 5 Metas, a serem cumpridas até 2022: 1) toda criança e jovem de 4 a 17 anos na escola; 2) toda criança plenamente alfabetizada até os 8 anos; 3) todo aluno com aprendizado adequado ao seu ano; 4) todo jovem de 19 anos com Ensino Médio concluído; e 5) investimento em Educação ampliado e bem gerido.

9 O Plano Nacional de Educação 20112021 sofreu no governo Lula da Silva uma intervenção do Plano de Desenvolvimento da Educação - PDE, que como Plano de Metas articulou programas e projetos fundamentais para a condução da gestão gerencial das políticas educacionais no Brasil mediante editais, incluindo o financiamento e a gestão dos recursos diretamente às escolas. O Plano Nacional de Educação atual (20142024) encontra-se comprometido em sua execução pela PEC do teto de gastos.

10 A Base Nacional Comum Curricular está em discussão desde 2015 e teve a versão final homologada em dezembro de 2017. A BNCC é apresentada como um documento de caráter normativo referência para as escolas e sistemas de ensino na elaboração de seus currículos. Críticas a essa política têm sido construídas em torno de seu potencial de aglutinar interesses do capital internacional na formulação das competências necessárias para os trabalhadores brasileiros. 
A participação do setor privado na educação pública também na venda de provas preparatórias locais para a avaliação em larga escala desenvolvida em âmbito nacional, além da gestão de escolas públicas por organizações sociais, o que tem representado uma reforma empresarial na educação básica (FREITAS, 2012; 2014; 2016).

No caso específico da educação infantil, a já consagrada transferência direta de recursos para unidades privadas sem fins lucrativos também entra na conta da mercantilização. A ampliação e aprofundamento do processo se dá agora também pela compra de vagas em unidades privadas com fins de lucro. ${ }^{11}$

Já na educação especial, a oferta do atendimento educacional especializado em um modelo único articulado pela política oficial na sala de recursos multifuncional além de estar longe de ser universalizado, foi estruturado em torno de kits fixos de materiais e recursos. As organizações sociais, a exemplo do que acontece na educação infantil, atuam firmes e fortes no setor com transferência de recursos públicos para o setor privado-assistencial. Um desdobramento desse processo é a formalização das instituições de educação especial mantidas pelas Associações de Pais e Amigos dos Excepcionais - APAEs como escolas de educação básica na modalidade educação especial. Tal situação já se encontra em curso no Paraná desde 2009 (ROSSETTO e PIAIA, 2015) e teve parecer aprovado recentemente no Conselho Estadual de Educação de Santa Catarina..$^{12} \mathrm{O}$ governo Bolsonaro vem contribuindo para o aprofundamento dessa linha de privatizações na Educação Especial com a proposição de uma "atualização" das políticas para o setor, em tramitação no Conselho Nacional de Educação.

Se articularmos o binômio mercantilização/democratização como antagônicos, vamos afirmar os riscos da democracia "como poder popular", em relação à educação básica, que certamente ganhou novas definições e aprofundamento do processo após 2016.

A educação básica pública no Brasil foi tematizada na Revista Valor Econômico como responsável por cerca de $80 \%$ das matrículas, ${ }^{13}$ diferente da educação superior no país que é predominantemente privada. A tematização por uma revista de economia retrata uma apreensão da educação como nicho de mercado. Podemos pensar que um dos efeitos da compulsoriedade de matrículas/obrigatoriedade de freqüência, ao longo do processo de política de educação para todos capitaneado pelo Banco Mundial e UNESCO, foi a configuração da educação básica como um nicho de mercado a ser explorado. $O$ tratamento dessas políticas educacionais como políticas de inclusão ao sistema educacional e à ordem social representou, mediante práticas de coesão social, uma articulação da classe trabalhadora à democra-
11 A título de exemplo segue edital de uma prefeitura no Rio Grande do Sul: http://www.sapucaiadosul.rs.gov.br/ prefeitura-credencia-escolas-de-educacao-infantil-para-compra-de-vagas/

12 Parecer CEE/CEB no 007 de 20 de fevereiro de 2018.

13 Publicação de 11 de setembro de 2017. 
cia burguesa. Ainda que o slogan do "direito à educação" tenha sido evocado no bojo de tais políticas e que objetivamente tenhamos mudanças importantes nos índices de acesso ao ensino fundamental, esse dado em si não significa um fortalecimento da classe trabalhadora e de um projeto de sociedade que almeje a emancipação humana. Sua defesa a partir de uma base conservadora tem promovido o consentimento da classe trabalhadora em relação ao acesso à educação básica e à busca por uma "qualidade" educacional que estaria disponível "para todos" em condições diferenciadas. Contudo, uma chave analítica para apreender o slogan do direito à educação que não a partir de uma base conservadora de pensamento é confrontá-lo com o conceito de expropriação secundária, tal como proposto por Fontes (2010).

$\mathrm{O}$ argumento segundo o qual a educação é um direito social fundamental está apoiado no dispositivo constitucional. Conforme a Constituição Federal no art. $6^{0}$ "São direitos sociais a educação, a saúde, a alimentação, o trabalho, a moradia, o transporte, o lazer, a segurança, a previdência social, a proteção à maternidade e à infância, a assistência aos desamparados, na forma desta Constituição". ${ }^{14} \mathrm{O}$ dispositivo legal no Brasil, assim como em outros países, não apaga a realidade de lutas da classe trabalhadora em constante movimento de conquistas e expropriações de direitos. A expansão capitalista sob a forma do imperialismo ao dinamizar as relações sociais, agregou novas determinações e expressões para expropriações contemporâneas ou secundárias (FONTES, 2010). Os processos de mercantilização dos direitos sociais podem ser entendidos como processos de expropriação secundária, uma vez que contribuem para renovar as garantias da acumulação de capital, condição permanente do capitalismo. Embora a educação conste no dispositivo constitucional como um direito social, sua mercantilização joga papel importante no processo de levar à frente o projeto educacional do capital, o que implica alienar a formação da classe trabalhadora ao estritamente necessário às condições exigidas pelo mercado.

Neves e Martins (2015) articulam reflexões importantes em seu livro "Educação Básica: tragédia anunciada" no qual analisam as relações estabelecidas entre o desenvolvimento do "capitalismo neoliberal de terceira via" no Brasil, desde os anos 1990, e suas articulações com o processo de formação humana para o trabalho simples que tem na educação escolar sua principal forma política. Segundo os autores

A formação para o trabalho simples no capitalismo neoliberal se materializa, portanto, na educação infantil, ensino fundamental e
14 Redação dada por BRASIL. Presidência da República. Emenda Constitucional no 90, de 2015. 
ensino médio, etapas da educação básica, e pode ser complementada por treinamentos de habilidades específicas para ocupação de postos de trabalho. A formação para o trabalho simples no Brasil urbano-industrial em seu conjunto e, especificamente, no capitalismo neoliberal fundamenta-se prioritariamente na concepção de mundo burguesa, preparando capital humano para o mercado de trabalho e disseminando entre os trabalhadores os valores caros à reprodução ampliada do capital e das relações sociais capitalistas, disciplinando-os para o empreendedorismo e para a colaboração (NEVES; MARTINS, 2015, p. 20).

A democracia burguesa reiterou nos últimos anos no Brasil mediante as políticas educacionais um direcionamento da formação da classe trabalhadora com base em articulação política de diferentes frações da burguesia sob dominação da fração financeira. Tal articulação vinha sendo feita em meio a processos de colaboração de setores organizados da classe trabalhadora, muitos dos quais compunham o governo federal. Um exemplo dessa dominação com expressão econômica é a desproporção entre a distribuição de renda via programas de renda mínima e pagamento de juros da dívida.

Segundo Souza, Melo E Bonatto (2015, p. 84), autores do coletivo mencionado, a distribuição de renda mínima no Brasil ocorreu subordinada aos ganhos do capital financeiro e visando ampliação do consumo interno de mercadorias.

No ano de 2010, o Programa Bolsa Família atingiu mais de 12,5 milhões de famílias, com um custo aproximado de R $\$ 13$ bilhões. Efetivamente, isso significou que o programa Bolsa Família representou nessa conjuntura algo em torno de $0,8 \%$ do PIB, atingindo um significativo contingente populacional, ao mesmo tempo em que o superávit primário e o pagamento de juros destinaram perto de $9 \%$ do PIB para as frações rentistas da burguesia, investidoras em títulos da dívida pública brasileira.

A associação de uma formação humana mediante políticas educacionais na direção do colaboracionismo entre classes coloca a democracia burguesa em destaque e fortalecimento. As políticas sociais dos governos Lula da Silva e Dilma Rousseff podem ter contribuído para o desenvolvimento de consentimentos ativos e passivos da classe trabalhadora e seus movimentos organizados em relação à formulação social capitalista. O desenvolvimento de uma 
"democracia consentida" foi constatado por Martins, Neves (2015, p. 160) como "uma relação social que se constrói por meio de princípios, práticas, estratégias e precisa de colaboração das classes trabalhadoras nessa construção". A democracia consentida, como tratada pelos autores aqui mencionados, é fortalecida pelo colaboracionismo entre classes como uma estratégia de redução ao universo da pequena política e tem uma forte face participativa, ainda que em relações de dominação.

Pensando com Gramsci (2007, p. 21),

[...] a pequena política compreende as questões parciais e cotidianas que se apresentam no interior de uma estrutura já estabelecida em decorrência de lutas pela predominância entre as diversas frações de uma mesma classe política. Portanto, é grande política tentar excluir a grande política do âmbito interno da vida estatal e reduzir tudo à pequena política.

Já as políticas sociais do governo Temer revelaram características coercitivas, articuladas pelo "assalto ao fundo público", com aprofundamento de restrições orçamentárias/contingenciamentos na área social. Representam na educação uma ampliação e verticalização dos processos de precarização escolar, podendo induzir ainda mais o deslocamento de frações mais bem remuneradas da classe trabalhadora para a oferta de educação privada e alimentar o mercado educacional agora também na educação básica, além de ampliar a oferta educacional privada mediante transferência de recursos públicos. ${ }^{15}$

A proposta de ampliação numérica do acesso à educação básica se deu em grande medida pela via de um rebaixamento formativo dimensionado pelo mercado e submetido a avaliações que o fazem parecer "de qualidade". No governo Temer a formação humana via educação escolar assumiu uma face menos humanizada do capital, ampliou o mercado para a formação de professores em cinco semanas nos moldes do Teach for America ${ }^{16}$ na face do Programa Ensina, ${ }^{17}$ colocou a juventude o mais cedo possível disponível para o mercado de trabalho ${ }^{18}$ ao mesmo tempo em que lhes retirou os direitos trabalhistas conquistados por gerações que os antecederam. Mediante a reforma do ensino médio, apontou para um horizonte de encurtamento da infância, empobreceu a formação escolar ao eliminar conteúdos e conhecimentos considerados no âmbito de tal projeto político como desnecessários à formação humana.

O projeto atual para o Brasil articulado pelo bloco no poder abandonou a proposição de uma "democracia consentida”. É mais afeito à coerção. É acompanhado por processos violentos de todas as forças policiais, judicialização
15 Foram registradas notícias de fusões e aquisições na educação básica semelhantes aquelas que temos acompanhado na educação superior: http:// www.revistaeducacao.com.br/setor-de-educacao-basica-entra-no-radar-dos-investidores/; https://g1.globo.com/ economia/negocios/noticia/kroton-deve-ir-as-compras-no-setor-de-educacao-basica-apos-veto-do-cade.ghtml; fusões no setor de educação passarão a mirar ensino básico: http://www.cnaconsultores.com.br/ultima-noticias-interno/item/410-fusoes_no_setor_de_ educacao_passarao

16 Programa de recrutamento de estudantes universitários para que se tornarem professores cem processo de treinamento rápido, vinculado ao Teach for All. https://www.teachforamerica.org

17 Startup brasileira articulada ao Teach for All. https://www.ensinabrasil.org

18 Vide Reforma do Ensino Médio, lei federal $n^{0} 13.415$ de 2017. 
da vida social e criminalização dos movimentos sociais. Tem familiaridade com as decisões de gabinete. Afirma uma democracia representativa, sem o pudor do poder de negociar com diferentes moedas os apoios que o sustentam no âmbito parlamentar. A representatividade da democracia burguesa, contudo, segue sendo sustentada pelos pilares do individualismo, da livre concorrência e da meritocracia. Os cortes orçamentários na forma de contingenciamento ou condicionamento de gastos na área da educação têm sido a tônica do governo Bolsonaro. Além disso, a nomeação de ministros sem afinidade com a pasta tem contribuído para a perda de norte em nível nacional, o que favorece que os conglomerados educacionais sejam reconhecidos como aqueles que poderão trazer soluções. Isso já está sendo registrado durante a pandemia do Covid-19, a qual ocasionou a interrupção dos calendários presenciais na educação básica e superior, e que colocou em pauta formas remotas de ensino. Cumpre destacar nesse tema a forte presença de empresas nacionais e estrangeiras ligadas às tecnologias de informação e comunicação que estão fornecendo plataformas digitais para as redes de ensino e universidades públicas, denotando mais uma vez a presença do mercado na educação.

Considerando esse breve percurso analítico, podemos afirmar que democracia "consentida" ou democracia "representativa" acompanhada por processos de repressão e conservadorismo são duas dentre as possíveis formas para a democracia burguesa, com variações relativas à estratégia política que o capital requer aos Estados nacionais.

\section{Considerações finais}

O esforço de reflexão produzido nesse texto teve como objetivo articular alguns elementos conceituais acerca da relação entre a conjuntura brasileira, a democracia e as políticas educacionais. A forma violenta que a política de modo geral, e a política educacional em particular vem sendo tratada desde 2016 é, sem sombra de dúvida, geradora de inquietação e insegurança. Contudo, buscamos discutir que não houve nas políticas educacionais ampliação ou estreitamento da democracia burguesa, ainda que possamos observar alterações na forma política pela qual ela passa a ser praticada. O mais significativo para aqueles que defendem uma educação pública, gratuita, de qualidade formativa com vistas à emancipação humana é, a meu ver, que as formas políticas em curso constituídas por violência, coerção, conservadorismo e buscando a redução da participação popular, contribuem, em primeira instância, para aprofundar a fragmentação e a desorganização da classe trabalhadora em torno de um projeto de educação e 
de sociedade. Portanto, o horizonte não é de risco à democracia burguesa, mas à democracia como poder popular, de risco à classe trabalhadora em todas as suas faces e formas de organização. Entretanto, contraditoriamente, as formas políticas em curso podem ser geradoras de resistência, de reflexão, de organização e articulação.

\section{Referências}

ADRIÃO, T.; PERONI, V. M. V. A educação pública e sua relação com o setor privado: implicações para a democracia educacional. Revista Retratos da Escola, Brasília, v. 3, n. 4, p. 107-116, jan./jun. 2009.

ADRIÃO, T.; GARCIA, T.; BORGHI, R.; ARELARO, L. Uma modalidade peculiar de privatização da educação pública: a aquisição de "sistemas de ensino" por municípios paulistas. Educação\&Sociedade, Campinas, v. 30, n. 108, p. 799-818, out. 2009.

ADRIÃO, T. Escolas charters nos EUA: contradições de uma tendência proposta para o Brasil e suas implicações para a oferta da educação pública. Educação e Filosofia, Uberlândia, v. 28, número especial, p. 263-282, 2014.

ADRIÃO, T. et al. Grupos empresariais na educação básica pública brasileira: limites à efetivação do direito à educação. Educação\&Sociedade, Campinas, v. 37, nº . 134, p.113-131, jan./mar., 2016.

ALVES, G. O grande assalto ao fundo público. Blog da Boitempo, 18 de agosto de 2016. Disponível em: https:// blogdaboitempo.com.br/2016/o8/16/o-grande-assalto-ao-fundo-publico-no-brasil/. Acesso em: 15 mar. 2020.

BIANCHI, A. O que é um golpe de Estado. Blog Junho, 26 março de 2016. Disponível em: blogjunho.com.br/o-que-e-um-golpe-de-estado. Acesso em: 15 mar. 2020.

BOITO JR., A. Estado e burguesia no capitalismo neoliberal. Revista de Sociologia Política. Curitiba, 28, p. 5773, jun. 2007.

BRASIL. Câmara dos Deputados. Proposta de Emenda à Constituição n. 241-A. Altera o ato das disposições constitucionais transitórias para instituir o Novo Regime Fiscal e dá outras providências. Brasília, 2016.

BRASIL. Presidência da República. Casa Civil. Emenda Constitucional n. 90, de 15 de setembro de 2015 . Dá nova redação ao artigo $6^{\circ}$ da Constituição Federal para introduzir o transporte como direito social. Brasília, 2015. 
BRASIL. Presidência da República. Lei Federal 13.415 de 16 de fevereiro de 2017. Brasília, 2017.

CHESNAIS, F. Mundialização: o capital financeiro no comando. Outubro, edição 5, 2001, p. 1-22.

CURSO sobre o golpe 2016 se espalha para universidades internacionais. Diário On Line - Causa Operária. 26 mar. 2018.

FONTES, V. Capital-imperialismo. Teoria e história. Rio de Janeiro. EdUFRJ, 2010.

FONTES, V. Capitalismo, imperialismo, movimentos sociais e lutas de classes. 2007. Mimeo.

FONTES, V. O núcleo central do governo Bolsonaro - o protofascismo. Esquerda Online. 2019, p. 1-7.

FREITAS, L. C. de. Os reformadores empresariais da educação: da desmoralização do magistério a destruição do sistema publico de educação. Educação\& Sociedade, Campinas, v. 33, n. 119, p. 379-404, abr./jun. 2012.

FREITAS, L. C. de. Os reformadores empresariais da educação e a disputa pelo controle do processo pedagógico na escola. Educação\& Sociedade, Campinas, v. 35, n. 129, p. 1085-1114, out./dez., 2014.

FREITAS, L. C. de. Três teses sobre as reformas empresariais da educação: perdendo a ingenuidade. Cadernos Cedes, Campinas, v. 36, n. 99, p. 137-153, maio-ago. 2016.

GRAMSCI, A. Cadernos do cárcere. V.3: Maquiavel notas sobre o Estado e a política. 3.ed. Civilização Brasileira, Rio de Janeiro, 2007.

GRANEMANN, S. Políticas sociais e financeirização dos direitos ao trabalho. Em Pauta. Revista da Faculdade de Serviço Social da Universidade do Estado do Rio de Janeiro. n. 20, 2007, p. 57-68.

HOBSBAWM, E. J. A era das revoluções. 9.edição. São Paulo: Paz e Terra, 1996.

KRAWCZYK, N. R. Políticas de regulação e mercantilização da educação: socialização para uma nova cidadania? Educação\& Sociedade, Campinas, v. 26, n. 92, p. 799819, Especial - outubro, 2005.

MARX, K. O capital. Volume I Livro Primeiro. Processo de produção do capital. Tradução de Regis Barbosa E Flávio R. Kothe. São Paulo: Nova Cultural, 1985. 
MÈSZÀROS, I. Igualdade substantiva e democracia substantiva. Blog da Boitempo. Disponível em: https:// blogdaboitempo.com.br/2017/12/19/meszaros-igualdade-substantiva-e-democracia-substantiva/. Acesso em: 15 mar. 2020.

NEVES, M.L.W. e MARTINS, A.S. (orgs.) Educação básica: tragédia anunciada. Rio de Janeiro: Xamã, 2015.

RANCIÈRE, J. O ódio à democracia. Tradução: Mariana Echalar. São Paulo: Boitempo, 2014.

ROSSETTO, E. e PIAIA, T. M. A escola de educação básica na modalidade de educação especial no estado do Paraná. Crítica Educativa (Sorocaba/SP), v..1, n.2, p. 98-109, jul./dez., 2015.

SANTA CATARINA. Conselho Estadual de Educação. Parecer 007, de 20 de fevereiro de 2018, que aprova o Reconhecimento das Associações de Pais e Amigos dos Excepcionais (APAEs/SC), no exercício do Ensino Básico na Modalidade de Educação Especial, credenciando as APAEs de Santa Catarina como Escolas Especiais. Florianópolis, SC, 2018.

VALOR ECONÔMICO. Ensino básico entra no radar dos grandes grupos. 17 de setembro de 2017. Disponível em: http://www.valor.com.br/empresas/511365o/ensino-basico-entra-no-radar-de-grandes-grupos. Acesso em: 15 mar. 2020.

WOOD, E. Capitalismo e democracia. In: CLACSO. A teoria marxista hoje: problemas e perspectivas. Buenos $\mathrm{Ai}-$ res, 2007.

Enviado em: 15-05-2018

Aceito em: 28-07-2020

Publicado em: 05-08-2020 